\title{
Agreement between clinical and histopathologic diagnoses and completeness of oral biopsy forms
}

\begin{abstract}
Marina MENDEZ(a)
Alex Nogueira HAAS ${ }^{(b)}$

Pantelis Varvaki RADOS(c)

Manoel SANT'ANA FILHO(c)

Vinicius Coelho CARRARD(c)
\end{abstract}

(a) Universidade Federal do Rio Grande do Sul - UFRGS, Dental School, Porto Alegre, RS, Brazil.

(b) Universidade Federal do Rio Grande do Sul - UFRGS, Dental School, Department of Periodontology, Porto Alegre, RS, Brazil.

(c) Universidade Federal do Rio Grande do Sul - UFRGS, Dental School, Department of Oral Pathology, Porto Alegre, RS, Brazil.

Declaration of Interests: The authors certify that they have no commercial or associative interest that represents a conflict of interest in connection with the manuscript.

Corresponding Author:

Vinicius Coelho Carrard

E-mail: vccarrard@gmail.com

DOI: 10.1590/1807-3107BOR-2016.vol30.0094

Submitted: Nov 16, 2015

Accepted for publication: Apr 25, 2016

Last revision: May 23, 2016

\begin{abstract}
The present study aimed to assess the rate of agreement between clinical and histopathological diagnoses and to report the frequency of completed forms for specimens that were subjected to histopathological examination and retrospectively examined. Data from 8,168 specimens submitted to histopathological examination were retrieved from the records. A total of 5,368 cases were included. Agreement was defined based on the definition of lesion nature according to its diagnostic category. Sensitivity, specificity, and positive and negative predictive values were calculated for each diagnostic category. The highest rate of agreement was observed for periapical lesions (92.6\%), followed by potentially malignant disorders (90.1\%) and non-neoplastic proliferative disorders $(89.3 \%)$. Low rates of histopathological confirmation of the clinical impression were observed for mesenchymal tumors (25.0\%) and cysts $(44.2 \%)$. Sensitivity values were $>0.70$ for all lesions, except for cysts $(0.51)$. Specificity was relatively high, ranging from 0.97 to 1.00 . The frequency of incomplete biopsy forms ranged from 16.8\% (malignant tumors of oral mucosal epithelium) to $51.0 \%$ (nonspecific inflammatory reaction). The most frequently completed biopsy forms corresponded to epithelial malignant tumors (83.2\%) and glandular inflammation (72.3\%). In conclusion, there was an acceptable level of agreement. The low level of completeness of biopsy forms indicates little awareness about the relevance of gathering detailed information during clinical examination.
\end{abstract}

Keywords: Biopsy; Diagnosis, Oral; Referral and Consultation; Diagnostic Errors.

\section{Introduction}

Lesions of the oral mucosa occur in approximately $30 \%$ of the general population $^{1,2}$. Unlike other parts of the body, the oral cavity allows good access for clinical examination. In the majority of cases involving oral mucosal lesions, clinical characteristics of the lesions can lead to a definitive diagnosis ${ }^{3}$. However, biopsy followed by microscopic examination is often necessary to confirm or refine a preliminary diagnosis ${ }^{4}$.

Discrepancies often occur between clinical impressions and histopathological diagnoses, with the latter considered the gold standard of oral mucosal lesions diagnosis ${ }^{5,6,7,8}$. In part, these discrepancies result from methodological differences in the criteria used for diagnosis and the professional performing the evaluations. 
It is debatable whether dental schools offer sufficient training in oral pathology and medicine during undergraduate courses ${ }^{6,9}$, and there is a lack of theoretical and practical skills in procedures related to these areas of knowledge ${ }^{10}$. These hypotheses are supported by the incidence of incomplete referral letters or forms that accompany specimens submitted for histopathological examination. When sufficient information is not provided, it is difficult to achieve an accurate histopathological diagnosis ${ }^{11,12}$.

Overall, the diagnostic process is challenging and can vary according to the nature of various diseases. However, the majority of previous studies failed to consider the peculiarities of different groups of lesions. Therefore, the present study aimed to assess the rate of agreement between clinical and histopathological diagnoses and to report the frequency of completed forms accompanying specimens that were subjected to histopathological examination and retrospectively examined.

\section{Methodology}

\section{Study design and sample}

Oral pathology records of 8,168 specimens that were submitted for histopathological examination by private and public health dental practitioners or obtained from undergraduate students of our institution between 1995 and 2004 were retrospectively analyzed. Data were retrieved and entered into a database by a single researcher.

The following cases were excluded: those involving research material specimens $(\mathrm{n}=688$, $8.4 \%$ ), descriptive reports with a lack of information and/or an insufficient amount of tissue $(n=650$, $7.9 \%$ ), and cases in which a clinical impression was not provided $(\mathrm{n}=1462,17.9 \%)$. The remaining cases $(n=5368)$ were included in this study.

Data obtained from each case included the identification number; patient age, sex, and skin color; date and type of biopsy; clinical impression; and histopathological diagnosis. Classification of the lesions according to the diagnostic category and most common diagnoses were previously described ${ }^{13}$.

\section{Ethical considerations}

The study protocol was approved by the Research and Ethics Committee of the School of Dentistry of the Federal University of Rio Grande do Sul (protocol no. 269/08) and was conducted in accordance with the principles of the Declaration of Helsinki. Data was anonymized and de-identified prior to analysis to guarantee patient confidentiality.

\section{Classification criteria}

Lesions were classified as inflammatory lesions, benign tumors, malignant tumors, or other according to the histological findings associated with each lesion. Inflammatory lesions were further subdivided into the following five categories: (1) immunologically mediated lesions, corresponding to lichen planus or pemphigus vulgaris; (2) non-neoplastic proliferative disorders (NNPDs), including reactional lesions induced by trauma, chemical, or biological agents, such as inflammatory fibrous hyperplasia, pyogenic granuloma, and peripheral giant cell granuloma; (3) periapical inflammatory lesions, corresponding to inflammatory tissue damage induced by the removal of necrotic pulp after tooth extraction or apical surgery; (4) nonspecific inflammatory reactions, such as chronic inflammatory tissue or granulation tissue; and (5) inflammatory glandular lesions, corresponding to a mucocele, ranula, or sialadenitis.

Benign tumors were also further subdivided into mesenchymal, odontogenic, epithelial (oral mucosal and glandular), and osseous. Malignant tumors were subdivided into epithelial (oral mucosal and glandular) and mesenchymal.

The "other" diagnosis group included the following: (1) potentially malignant disorders (e.g., leukoplakia and actinic cheilitis), among which leukoplakia was considered a clinical impression and not a definitive diagnosis; therefore, it was considered as a diagnostic category, resulting in the inclusion of a range of possible epithelial disturbances; (2) cysts, including odontogenic, non-odontogenic, and unspecified (inflammatory cysts were classified as inflammatory lesions.); (3) fibro-osseous and other bone-related lesions, including peripheral ossifying fibroma, periapical cemental dysplasia, and traumatic bone 
cysts; and (4) normal tissue, corresponding mainly to dental follicles and the labial/lingual frenum.

\section{Definition of agreement}

Agreement was achieved when the clinical and final diagnoses corresponded to the same diagnostic group according to the above-mentioned classification criteria.

\section{Completed forms}

The following information was requested on a standardized form that was referred to for the histopathological examinations: patient sex, age, and skin color; location of the lesion; type of biopsy; and clinical impression. If any of this information was not provided by the clinician, the form was considered incomplete.

\section{Statistical analysis}

Frequency distribution of clinical and histopathological diagnoses was used to describe the rate of agreement between the two diagnoses. Sensitivity, specificity, and positive and negative predictive values were calculated for each lesion, with the histopathological diagnosis used as the gold standard. Ninety-five percent confidence intervals were also reported. To determine the agreement of the most frequently observed cases and to avoid analytical bias based on diagnostic values, diagnostic analysis was performed only for the categories of oral lesions that included more than 50 cases.

Data were analyzed using STATA software (version 10 for Macintosh; STATA Corp., College Station, TX, USA). The unit of analysis was each individual, and the level of significance was $5 \%$.

\section{Results}

Table 1 lists the rates of agreement between the clinical and histopathological diagnoses for each group of clinical impression. The highest rate of agreement $(92.6 \%)$ was observed for periapical

Table 1. Percentage of agreement between clinical and histopathologic diagnoses for each group of clinical diagnosis.

\begin{tabular}{|c|c|c|c|c|}
\hline \multirow{2}{*}{ Clinical diagnosis } & \multirow{2}{*}{$\begin{array}{l}\text { Total clinical } \\
\text { cases (n) }\end{array}$} & \multirow{2}{*}{$\begin{array}{l}\text { Histopathologic } \\
\text { confirmation (\%) }\end{array}$} & \multicolumn{2}{|l|}{ Most frequent diagnostic error } \\
\hline & & & Subgroup & $\%$ \\
\hline \multicolumn{5}{|l|}{ Inflammatory lesions } \\
\hline Periapical lesions & 1,720 & 92.6 & Nonspecific inflammatory reaction & 6.3 \\
\hline Nonneoplastic proliferative disorders & 718 & 89.3 & Mesenchymal benign tumor & 3.1 \\
\hline Immunologically mediated lesions & 35 & 80.0 & Potentially malignant disorders & 14.3 \\
\hline Nonspecific inflammatory reaction & 49 & 77.5 & Nonneoplastic proliferative disorders & 8.2 \\
\hline Glandular inflammation & 195 & 83.6 & Mesenchymal benign tumor & 7.2 \\
\hline \multicolumn{5}{|l|}{ Benign tumors } \\
\hline Mesenchymal & 278 & 71.2 & Nonneoplastic proliferative disorders & 16.9 \\
\hline Odontogenic & 89 & 78.7 & Normal tissue & 5.6 \\
\hline Oral mucosal epithelium & 103 & 53.4 & Nonneoplastic proliferative disorders & 25.2 \\
\hline Glandular epithelium & 15 & 66.7 & $\begin{array}{l}\text { Mesenchymal benign and glandular } \\
\text { malignant tumor }\end{array}$ & 13.3 \\
\hline Bone & 8 & 75.0 & $\begin{array}{l}\text { Nonneoplastic proliferative disorders and } \\
\text { Bone pathology }\end{array}$ & 12.5 \\
\hline \multicolumn{5}{|l|}{ Malignant Tumors } \\
\hline Oral Mucosal epithelium & 101 & 77.2 & Nonneoplastic proliferative disorders & 6.9 \\
\hline Mesenchymal & 4 & 25.0 & $\begin{array}{c}\text { Malignant oral epithelial tumor, Nonspecific } \\
\text { inflammatory reaction and other } \\
\text { inflammatory lesions }\end{array}$ & 25.0 \\
\hline \multicolumn{5}{|l|}{ Others } \\
\hline Potentially malignant disorders & 132 & 90.1 & Immunologically mediated lesions & 5.3 \\
\hline Cysts & 154 & 44.2 & Normal tissue & 26.0 \\
\hline Fibro-osseous and other bone-related lesions & 21 & 76.2 & Nonneoplastic proliferative disorders & 14.3 \\
\hline
\end{tabular}


lesions, followed by potentially malignant disorders (90.1\%) and NNPDs (89.3\%). Low rates of agreement were observed for mesenchymal tumors $(25.0 \%)$ and cysts $(44.2 \%)$. Among the inflammatory lesions, $14.3 \%$ of the cases that were clinically diagnosed as immunologically mediated lesions were histologically confirmed to be potentially malignant lesions. The most frequent misdiagnosis involved normal tissue corresponding to dental follicle tissue in cases clinically diagnosed as cysts $(26.0 \%)$.

Sensitivity, specificity, and positive and negative predictive values for the lesion groups are reported in Table 2. Sensitivity values were $>0.70$ for all lesions, except for cysts (0.51). These results suggest that clinical impression has a high probability of appropriately detecting lesions that are subsequently confirmed by histopathology. Specificity ranged from 0.97 to 1.00 , thereby demonstrating that the capacity of clinical impression to detect healthy tissues is even greater than its capacity to detect disease.

The frequency of completed biopsy forms and the types of biopsy performed are presented in Table 3. The frequency of incomplete biopsy forms ranged from $16.8 \%$ (involving malignant tumors of the oral mucosal epithelium) to $51.0 \%$ (involving nonspecific inflammatory reactions). The most frequently completed biopsy forms were associated with epithelial malignant tumors (83.2\%) and glandular inflammation (72.3\%). The number of excisional and incisional biopsies varied among each diagnostic group. Incisional biopsies were performed for $77.1 \%$ and $82.2 \%$ of immunologically mediated lesions and malignant tumors of the oral mucosal epithelium, respectively. Alternatively, excisional biopsies were performed for $71.6 \%$ of benign tumors of mesenchymal origin, $71.8 \%$ of benign tumors of epithelial origin, and $76.4 \%$ of glandular inflammatory lesions. The number of non-informed type of biopsies ranged from 9.9\% (involving epithelial tumors) to $44.9 \%$ (for nonspecific inflammatory reactions). Incomplete data were provided for $31.3 \%$ and $31.8 \%$ of cases of periapical lesions and cysts, respectively.

\section{Discussion}

In this study, the rate of agreement between clinical and histopathological diagnoses was examined, as well as the rate of completed biopsy forms for specimens submitted to a Brazilian oral pathology laboratory. These considerations are valuable for improving

Table 2. Diagnostic tests for each type of lesion.

\begin{tabular}{|c|c|c|c|c|}
\hline Lesions & Sensitivity & Specificity & $\begin{array}{l}\text { Positive predictive } \\
\text { value }\end{array}$ & $\begin{array}{c}\text { Negative predictive } \\
\text { value }\end{array}$ \\
\hline \multicolumn{5}{|l|}{ Inflammatory lesions } \\
\hline Periapical lesions & $0.99(0.98-1.00)$ & $0.97(0.96-0.98)$ & $0.93(0.91-0.94)$ & $0.99(0.98-1.00)$ \\
\hline Nonneoplastic proliferative disorders & $0.85(0.82-0.87)$ & $0.98(0.98-0.99)$ & $0.89(0.87-0.91)$ & $0.98(0.97-0.99)$ \\
\hline Immunologically mediated lesions & $0.80(0.63-0.92)$ & $0.99(0.99-1.00)$ & $0.80(0.63-0.92)$ & $0.99(0.99-1.00)$ \\
\hline Glandular inflammation & $0.93(0.88-0.96)$ & 0.99 (0.99-0.99) & $0.84(0.78-0.89)$ & $1.00(1.00-1.00)$ \\
\hline \multicolumn{5}{|l|}{ Benign tumors } \\
\hline Mesenchymal & $0.79(0.74-0.84)$ & $0.98(0.98-0.98)$ & $0.71(0.67-0.76)$ & $0.99(0.99-0.99)$ \\
\hline Odontogenic & $0.74(0.64-0.83)$ & $1.00(0.99-1.00)$ & $0.79(0.69-0.87)$ & $1.00(0.99-1.00)$ \\
\hline Oral mucosal epithelium & $0.81(0.70-0.90)$ & $0.99(0.99-0.99)$ & $0.53(0.43-0.63)$ & $1.00(0.99-1.00)$ \\
\hline \multicolumn{5}{|l|}{ Malignant Tumors } \\
\hline Oral mucosal epithelium & $0.89(0.80-0.94)$ & $1.00(0.99-1.00)$ & $0.77(0.68-0.85)$ & $1.00(1.00-1.00)$ \\
\hline \multicolumn{5}{|l|}{ Others } \\
\hline Potentially malignant disorders & $0.86(0.79-0.91)$ & $1.00(1.00-1.00)$ & $0.91(0.84-0.95)$ & $1.00(0.99-1.00)$ \\
\hline Cysts & $0.51(0.42-0.60)$ & $0.98(0.98-0.99)$ & $0.44(0.36-0.53)$ & $0.99(0.98-0.99)$ \\
\hline
\end{tabular}


Table 3. Distribution (percentage in parentheses) of completeness of biopsy forms and type of biopsy for the most frequent histopathologic diagnoses.

\begin{tabular}{|c|c|c|c|c|c|}
\hline \multirow{2}{*}{ Histopathologic diagnoses } & \multicolumn{2}{|c|}{ Complete form } & \multicolumn{3}{|c|}{ Type of Biopsy } \\
\hline & Yes & No & Excisional & Incisional & Not Informed \\
\hline \multicolumn{6}{|l|}{ Inflammatory lesions } \\
\hline Periapical lesions & $1058(61.5)$ & $662(38.5)$ & $1145(66.6)$ & $36(2.1)$ & $539(31.3)$ \\
\hline Nonneoplastic proliferative disorders & $450(62.7)$ & $268(37.3)$ & 469 (65.3) & $53(7.4)$ & $196(27.3)$ \\
\hline Immunologically mediated lesions & $23(65.7)$ & $12(34.3)$ & $2(5.7)$ & $27(77.1)$ & $6(17.2)$ \\
\hline Nonspecific inflammatory reaction & $24(49.0)$ & $25(51.0)$ & $23(46.9)$ & $4(8.2)$ & $22(44.9)$ \\
\hline Glandular inflammation & $141(72.3)$ & $54(27.7)$ & $149(76.4)$ & $12(6.2)$ & $34(17.4)$ \\
\hline \multicolumn{6}{|l|}{ Benign Tumors } \\
\hline Mesenchymal & $174(62.6)$ & $104(37.4)$ & $199(71.6)$ & $3(1.1)$ & $76(27.3)$ \\
\hline Odontogenic & $53(59.6)$ & $36(40.4)$ & $41(46.2)$ & $28(31.4)$ & $20(22.4)$ \\
\hline Oral mucosal epithelium & $67(65.0)$ & $36(35.0)$ & $74(71.9)$ & $2(1.9)$ & $27(26.2)$ \\
\hline \multicolumn{6}{|l|}{ Malignant Tumor } \\
\hline Oral mucosal epithelium & $84(83.2)$ & $17(16.8)$ & $8(7.9)$ & $83(82.2)$ & $10(9.9)$ \\
\hline \multicolumn{6}{|l|}{ Others } \\
\hline Potentially malignant disorders & $97(73.5)$ & $35(26.5)$ & $60(45.5)$ & $46(34.8)$ & $26(19.7)$ \\
\hline Cysts & $90(58.4)$ & $64(41.6)$ & $86(55.8)$ & $19(12.4)$ & $49(31.8)$ \\
\hline
\end{tabular}

knowledge about the attitude and behavior of dentists and dental students regarding the requirement of histopathological examination. The present findings indicate that the levels of agreement ranged from moderate to high. In contrast, there were discrepancies in the completed biopsy forms, and the frequency of completion was relatively low for some pathologic categories. However, it is difficult to directly compare these results with those of other studies because of the remarkable differences in methodologies, mainly regarding the agreement criteria and the professionals that performed the evaluations $\mathrm{s}^{7,8}$.

In the present study, flexible criteria were used to compare clinical and histopathological diagnoses. For example, if the referral letter indicated that the clinical impression was a "periapical inflammatory lesion" or was any particular entity within this type of lesion (i.e., periapical abscess, granuloma, or cyst), and the microscopic evaluation revealed a diagnosis that did not exactly correspond to these entities, but belonged to the same diagnostic category ("periapical inflammatory lesion"), the case was considered to have agreement. This approach was used because clinical and radiographic examinations are not sufficient to support a specific diagnosis in this pathologic category ${ }^{14}$. In the present study, periapical lesions showed a high level of agreement, which was confirmed by diagnostic tests. Nevertheless, a substantially high number of incomplete biopsy forms and a lack of information regarding biopsy type were observed. In most cases, periapical radiolucencies correspond to inflammatory processes caused by pulp necrosis ${ }^{15}$. Considering these characteristics, dentists are usually confident about the final diagnosis ${ }^{16}$. It is hypothesized that this confidence is the most probable reason for the low rate of completed forms, particularly with regard to biopsy type. However, other diagnoses, including keratocysts ${ }^{15}$, giant cell granulomas ${ }^{17}$, and schwanomas ${ }^{18}$, although rare, may mimic inflammatory periapical lesions. Therefore, the importance of periapical radiographic images should not be underestimated by clinicians.

Oral immunologically mediated lesions were found to correspond mainly to lichen planus and pemphigus vulgaris. The former was included in this group of lesions because it is widely accepted as an immune disorder ${ }^{19}$. However, there is a consensus that, for some cases, the definition of this diagnosis remains challenging ${ }^{20}$. Therefore, a higher rate of disagreement observed for cases of lichen planus 
could be an expected finding, mainly in relation to oral leukoplakia ${ }^{21}$. The differential diagnosis between these pathologic entities may be difficult, particularly when clinical and histopathologic findings are not compatible ${ }^{20,22}$. However, the high performance for the oral immunologically mediated lesions group in the diagnostic tests indicates that dentists had reasonable skills to diagnose this group of lesions. It is also important to highlight that an incisional biopsy was performed for $77.1 \%$ of these cases, consistent with the recommended approach for immunologically mediated lesions ${ }^{23,24,25}$.

In relation to potentially malignant disorders, the high rate of agreement was an unexpected result. This could be explained by the flexible criteria adopted for the analysis that considered the limitations of clinical oral examination ${ }^{26}$, by which the clinical impression of leukoplakia was considered compatible with any epithelial disturbances.

In the present study, lesions clinically diagnosed as benign mesenchymal tumors were mostly misdiagnosed as NNPDs. Both diseases clinically present as soft tissue nodules ${ }^{27}$ and exhibit benign behavior. Consequently, some professionals may not be concerned about the final diagnosis defined by histopathological examination ${ }^{16}$. In fact, it is sometimes difficult to establish an accurate preliminary diagnosis for these groups of lesions based solely on clinical presentation ${ }^{28}$. Regarding the completeness of the biopsy forms for this group, a considerable number of forms had missing information. However, excisional biopsies were most frequently performed, consistent with the recommendations in the literature for benign mesenchymal tumors ${ }^{24}$.

Interestingly, more than half of benign tumors of the oral mucosal epithelium, which correspond to papillomas, were clinically suspected to be simple reactive lesions. In our study, those cases corresponded to inflammatory hyperplasia and pyogenic granuloma, which eventually develop an irregular or lobulated surface, mimicking a papilloma ${ }^{29,30}$. However, this misdiagnosis was not implicated in different therapeutic approaches because such lesions are treated by surgical excision.

Although there was a high rate of histopathologic confirmation $(83.6 \%)$ for glandular inflammation (mucocele), $7.2 \%$ of cases were misdiagnosed as benign mesenchymal tumors. These cases corresponded to hemangiomas, fibromas, and lipomas. A hemangioma is bluish in color, resembling a mucocele, and occurs relatively most commonly in the lower lip. Superficial mucoceles may present as nodules, such as fibromas ${ }^{31}$. Lipoma was not considered in the referred cases because this lesion does not frequently occur in the lips ${ }^{32}$, probably because the soft consistency of the tissue may simulate the presence of mucous, leading to a clinical impression of a mucocele ${ }^{33}$. In relation to these data, the clinician should consider another diagnostic hypothesis apart from a mucocele for a nodule in the lower lip.

The level of diagnostic accuracy reported for cases of oral squamous cell carcinoma, the main malignant tumor of the oral mucosal epithelium, varies considerably in the literature ${ }^{21,26,34}$. These lesions are often detected at an advanced stage when they clearly present clinical features of malignancy, thereby reducing the difficulty in making a diagnosis ${ }^{35}$. Therefore, a higher rate of agreement would be expected. Regarding the type of biopsy performed, an incisional approach was most often selected, consistent with the recommendations for suspicious lesions ${ }^{24}$. In the group of malignant tumors of the oral mucosal epithelium, NNPD was the most frequent misdiagnosis. This may be because of the presence of tissue proliferation and ulcerative regions in these lesions, which is in accordance with previous studies ${ }^{16,27}$. Considering these data, it is recommended that every oral mucosal mass should be biopsied to rule out malignancy ${ }^{27}$. Furthermore, the number of completed biopsy forms for this group was high, thereby reflecting the concern of dentists to accurately recognize malignant lesions.

In the cyst group, the main source of disagreement was dentigerous cysts, which can be misdiagnosed as normal tissue (i.e., a dental follicle). Saravana and Subhashraj reported that up to $46 \%$ of cystic changes detected by radiographic evaluations occurred in apparently normal dental follicles ${ }^{36}$. Furthermore, Wali et al. demonstrated that the thickness of the follicular space was not associated with the presence of cystic changes, and therefore, should not be used as a parameter for a presumptive diagnosis ${ }^{37}$. Regarding the results of the diagnostic tests performed in the present study, the 
cysts group was characterized by low sensitivity and positive predictive values, along with high specificity and negative predictive values. These results support the recommendation that a differential diagnosis between a dentigerous cyst and dental follicle should not only be based on clinical and radiographic findings. Our findings show that dentists were not able to consistently detect cystic lesions, particularly dentigerous cysts. Conversely, dentists exhibited a reasonable accuracy in defining when cystic lesions were absent. It is possible that the lack of clinical information in the biopsy forms contributed to these results.

A close dialogue between clinicians and oral pathologists is clearly desirable, and it is partially dependent on the information provided in referral forms ${ }^{12}$. Incomplete biopsy forms can contribute to the difficulties associated with specimen interpretation and can lead to descriptive or inconclusive reports ${ }^{38,39}$. Consequently, it is important to emphasize that both clinical and pathologic findings contribute to the accuracy of final diagnosis ${ }^{40}$. Initiatives such as the clinical referral guidelines proposed by Seoane et al. ${ }^{6}$ are recommended to improve diagnostic skills and potentially improve the early detection and treatment of several diseases, including oral cancer.

It is well-known that complete information obtained by clinicians is important for the diagnostic process. Missing information can delay a final

\section{References}

1. Shulman JD, Beach MM, Rivera-Hidalgo F. The prevalence of oral mucosal lesions in U.S. adults: data from the Third National Health and Nutrition Examination Survey, 1988-1994. J Am Dent Assoc. 2004;135(9):1279-86. doi:10.14219/jada.archive.2004.0403

2. Carrard V, Haas A, Rados P, Filho MS, Opperman $\mathrm{R}$, Albandar J et al. Prevalence and risk indicators of oral mucosal lesions in an urban population from South Brazil. Oral Dis. 2011;17(2):171-9. doi:10.1111/j.1601-0825.2010.01712.x

3. Eusterman VD. History and physical examination, screening and diagnostic testing. Otolaryngol Clin North Am. 2011;44(1):1-29. doi:10.1016/j.otc.2010.10.001

4. Melrose RJ, Handlers JP, Kerpel S, Summerlin DJ, Tomich CJ. The use of biopsy in dental practice. The position of the American Academy of Oral and Maxillofacial Pathology. Gen Dent. 2007;55(5):457-61. diagnosis and potentially further influence disease outcome and prognosis ${ }^{4,11}$. There were limitations associated with the present study, such as a lack of formal distinction among the specialties or professions of the submitting clinicians. This information could improve the present data because the experience and training of practitioners submitting specimens has the potential to influence their diagnostic capacity. In addition, the lack of standardized and detailed data collection was a limitation of this study.

In conclusion, an acceptable level of agreement was found in the present Brazilian oral pathology laroratory. The low rate of completed biopsy forms indicates the need to increase awareness regarding the relevance of gathering detailed information during a clinical examination. Furthermore, these findings reinforce that health professionals need to follow all steps of the diagnostic process to obtain findings that can be used to establish a definitive diagnosis.

\section{Acknowledgments}

The authors would like to thank Dr. João Jorge Diniz Barbachan (in memoriam) for his contribution to the Oral Pathology Laboratory of our institution. This study was partially funded by a PIBIC grant from the National Council of Scientific and Technological Development (CNPq).

5. Williams HK, Hey AA, Browne RM. The use by general dental practitioners of an oral pathology diagnostic service over a 20-year period: the Birmingham Dental Hospital experience. Br Dent J. 1997;182(11):424-9. doi:10.1038/sj.bdj.4809403

6. Seoane J, Varela-Centelles PI, Ramírez JR, Cameselle-Teijeiro J, Romero MA. Artefacts in oral incisional biopsies in general dental practice: a pathology audit. Oral Dis. 2004;10(2):113-7. doi:10.1111/j.1354-523X.2003.00983.x

7. Sardella A, Demarosi F, Lodi G, Canegallo L, Rimondini L, Carrassi A. Accuracy of referrals to a specialist oral medicine unit by general medical and dental practitioners and the educational implications. J Dent Educ. 2007;71(4):487-91.

8. Patel KJ, De Silva HL, Tong DC, Love RM. Concordance between clinical and histopathologic diagnoses of oral mucosal lesions. J Oral Maxillofac Surg. 2011;69(1):125-33. doi:10.1016/j.joms.2010.07.075 
9. Diamanti N, Duxbury AJ, Ariyaratnam S, Macfarlane TV. Attitudes to biopsy procedures in general dental practice. Br Dent J. 2002;192(10):588-92. doi:10.1038/sj.bdj.4801434

10. Wan A, Savage NW. Biopsy and diagnostic histopathology in dental practice in Brisbane: usage patterns and perceptions of usefulness. Aust Dent J. 2010;55(2):162-9. doi:10.1111/j.1834-7819.2010.01210.x

11. Jenkins RM. Quality of general practitioner referrals to outpatient departments: assessment by specialists and a general practitioner. Br J Gen Pract. 1993;43(368):111-3.

12. Piterman L, Koritsas S. Part II. General practitioner-specialist referral process. Intern Med J. 2005;35(8):491-6. doi:10.1111/j.1445-5994.2005.00860.x

13. Mendez M, Carrard VC, Haas AN, Lauxen IS, Barbachan JJ, Rados PV et al. A 10-year study of specimens submitted to oral pathology laboratory analysis: lesion occurrence and demographic features. Braz Oral Res. 2012;26(3):235-41. doi:10.1590/S1806-83242012000300009

14. Kuc I, Peters E, Pan J. Comparison of clinical and histologic diagnoses in periapical lesions. Oral Surg Oral Med Oral Pathol Oral Radiol Endod. 2000;89(3):333-7. doi:10.1016/S1079-2104(00)70098-9

15. Carrillo C, Penarrocha M, Ortega B, Martí E, Bagán JV, Vera F. Correlation of radiographic size and the presence of radiopaque lamina with histological findings in 70 periapical lesions. J Oral Maxillofac Surg. 2008;66(8):1600-5. doi:10.1016/j.joms.2007.11.024

16. Melrose RJ. Failure to diagnose pathology: an avoidable complication in oral and maxillofacial surgery. Oral Maxillofac Surg Clin North Am. 2011;23(3):465-73. doi:10.1016/j.coms.2011.04.008

17. Lombardi T, Bischof M, Nedir R, Vergain D, Galgano C, Samson J et al. Periapical central giant cell granuloma misdiagnosed as odontogenic cyst. Int Endod J. 2006;39(6):510-5. doi:10.1111/j.1365-2591.2006.01107.x

18. Martins MD, Taghloubi SA, Bussadori SK, Fernandes KP, Palo RM, Martins MA. Intraosseous schwannoma mimicking a periapical lesion on the adjacent tooth: case report. Int Endod J. 2007;40(1):72-8. doi:10.1111/j.1365-2591.2006.01195.x

19. Payeras MR, Cherubini K, Figueiredo MA, Salum FG. Oral lichen planus: focus on etiopathogenesis. Arch Oral Biol. 2013;58(9):1057-69. doi:10.1016/j.archoralbio.2013.04.004

20. Waal I. Oral lichen planus and oral lichenoid lesions; a critical appraisal with emphasis on the diagnostic aspects. Med Oral Patol Oral Cir Bucal. 2009;14(7):E310-4.

21. López-Jornet $\mathrm{P}$, Camacho-Alonso F, Martinez-Beneyto $Y$, Seoane-Leston J. Influence of years of professional experience in relation to the diagnostic skill of general dental practitioners (GDPs) in identifying oral cancer and precancerous lesions. Int Dent J. 2008;58(3):127-33. doi:10.1111/j.1875-595X.2008.tb00187.x

22. Meij EH, Waal I. Lack of clinicopathologic correlation in the diagnosis of oral lichen planus based on the presently available diagnostic criteria and suggestions for modifications. J Oral Pathol Med. 2003;32(9):507-12. doi:10.1034/j.1600-0714.2003.00125.x

23. Oliver RJ, Sloan P, Pemberton MN. Oral biopsies: methods and applications. Br Dent J. 2004;196(6):329-33. doi:10.1038/sj.bdj.4811075

24. Mota-Ramírez A, Silvestre FJ, Simó JM. Oral biopsy in dental practice. Med Oral Patol Oral Cir Bucal. 2007;12(7):E504-10.

25. Rosebush MS, Anderson KM, Rawal SY, Mincer HH, Rawal YB. The oral biopsy: indications, techniques and special considerations. J Tenn Dent Assoc. 2010;90(2):17-20.

26. Epstein JB, Güneri P, Boyacioglu H, Abt E. The limitations of the clinical oral examination in detecting dysplastic oral lesions and oral squamous cell carcinoma. J Am Dent Assoc. 2012;143(12):1332-42. doi:10.14219/jada.archive.2012.0096

27. Allon I, Kaplan I, Gal G, Chaushu G, Allon DM. The clinical characteristics of benign oral mucosal tumors. Med Oral Patol Oral Cir Bucal. 2014;19(5):e438-43. doi:10.4317/medoral.19387

28. Patil S, Rao RS, Sharath S, Agarwal A. True fibroma of alveolar mucosa. Case Rep Dent. 2014;2014:ID904098. doi:10.1155/2014/904098

29. Vaz Goulart MC, Lara VS. Inflammatory papillary hyperplasia of the palate: quantitative analysis of candida albicans and its negative correlation with microscopic and demographic aspects. Int J Prosthodont. 2011;24(3):235-7.

30. Gonçales ES, Damante JH, Fischer Rubira CM, Taveira LA. Pyogenic granuloma on the upper lip: an unusual location. J Appl Oral Sci. 2010;18(5):538-41. doi:10.1590/S1678-77572010000500019

31. Conceição JG, Gurgel CA, Ramos EA, De Aquino Xavier FC, Schlaepfer-Sales CB, Cangussu MC, et al. Oral mucoceles: a clinical, histopathological and immunohistochemical study. Acta Histochem. 2014;116(1):40-7. doi:10.1016/j.acthis.2013.04.015

32. Fregnani ER, Pires FR, Falzoni R, Lopes MA, Vargas PA. Lipomas of the oral cavity: clinical findings, histological classification and proliferative activity of 46 cases. Int J Oral Maxillofac Surg. 2003;32(1):49-53. doi:10.1054/ijom.2002.0317

33. Furlong MA, Fanburg-Smith JC, Childers EL. Lipoma of the oral and maxillofacial region: site and subclassification of 125 cases. Oral Surg Oral Med Oral Pathol Oral Radiol Endod. 2004;98(4):441-50. doi:10.1016/j.tripleo.2004.02.071

34. Mehrotra R, Gupta DK. Exciting new advances in oral cancer diagnosis: avenues to early detection. Head Neck Oncol. 2011;3(1):33. doi:10.1186/1758-3284-3-33

35. Kujan O, Glenny AM, Sloan P. Screening for oral cancer. Lancet. 2005;366(9493):1265-6. doi:10.1016/S0140-6736(05)67524-1

36. Saravana GH, Subhashraj K. Cystic changes in dental follicle associated with radiographically normal impacted mandibular third molar. Br J Oral Maxillofac Surg. 2008;46(7):552-3. doi:10.1016/j.bjoms.2008.02.008 
37. Wali GG, Sridhar V, Shyla HN. A study on dentigerous cystic changes with radiographically normal impacted mandibular third molars. J Maxillofac Oral Surg. 2012;11(4):458-65. doi:10.1007/s12663-011-0252-7

38. Jones K, Jordan RC. Patterns of second-opinion diagnosis in oral and maxillofacial pathology. Oral Surg Oral Med Oral Pathol Oral Radiol Endod. 2010;109(6):865-9. doi:10.1016/j.tripleo.2009.12.023
39. Kumaraswamy KL, Vidhya M, Rao PK, Mukunda A. Oral biopsy: oral pathologist's perspective. J Cancer Res Ther. 2012;8(2):192-8. doi:10.4103/0973-1482.98969

40. Rad M, Hashemipoor MA, Mojtahedi A, Zarei MR, Chamani G, Kakoei S et al. Correlation between clinical and histopathologic diagnoses of oral lichen planus based on modified WHO diagnostic criteria. Oral Surg Oral Med Oral Pathol Oral Radiol Endod. 2009;107(6):796-800. doi:10.1016/j.tripleo.2009.02.020 